\title{
Dystocia in Timorensis Deer: a case report
}

\author{
ZKH Jeber ${ }^{1}$, AC Amat ${ }^{2}$, FF Jesse ${ }^{2}$ and AW Haron ${ }^{* 2}$ \\ Department of Clinical Studies, Faculty of Veterinary Medicine, Universiti Putra Malaysia.
}

\begin{abstract}
In this case, a female Timorensis deer (Cervus timorensis) belong to Taman Pertanian Universiti (TPU), Universiti Putra Malaysia (UPM), was in labour for 5 hours. The limbs of the fawn were found hanging from the vulva at the general inspection. Request for veterinary assistance was initiated and the deer was isolated in dark room. Restraining was conducted physically without any tranquilizers or anaesthesia. On physical examination, foetus was found a live with posterior presentation and both hind limbs fully extended inside the birth canal. Manual traction was successfully performed to deliver the foetus. Following delivery the mother given proper care and the fawn was cleaned. The fawn was subsequently introduced to the mother and monitored to ensure suckling before being released to the farm.
\end{abstract}

Keywords: Timorensis Deer, Dystocia, Cervus timorensis

\section{Introduction}

Dystocia is described as difficult birth or abnormal birth (Aiello et al., 2005). Dystocia exist when delivery taking longer time than normal or some other events occur that make delivery difficult or even impossible. A dam consider in dystocia when she has been in active labor for $30 \mathrm{~min}$ or more and is not making any progress. The most common causes of dystocia are uterine inertia, inadequate size of birth canal (maternal factors) or over sized fetus, abnormal orientation of the fetus inside the birth canal (fetal factors), other factors which is less common such as feto-pelvic disproportion, twin birth, failure of the cervix to dilate (ring womb), diseases in mother, uterine rupture, uterine torsion, vaginal prolapsed and maternal immaturity (Aiello et al., 2005; Bliss, 1988). Most fetuses born in cranial anterior longitudinal presentation, dorsal position and their fore limbs extended, some other born in caudal longitudinal presentation (Engum and Lyngset, 1970).

Timorensis deer is member of the deer family inhibits South Asia (Semiadi et al., 1993), (China, Taiwan, Sumatra, Borneo) and Southeast Asia (Burma, Thailand, Indonesia, Peninsula Malaysia), although genetic analysis show that the closest relative to Timorensis deer is Sambar deer (Rusa unicolor) (Emerson and Tate, 1993). Timorensis deer live in tropical seasonal forests, subtropical mixed forests and they found around water most of the time (Timmins et al., 2008). They feed on variety of plants including grasses, foliage, fruits, water plants and wide variety of shrubs and trees. Female's deer moving widely among breeding territories seeking males to court. Gestation in deer lasts for about 8 months, though studies mention it might be longer. Only single fawn is born usually, although twins have been reported. The newborn fawn usually not spotted or lightly spotted in some sub species which disappears shortly after birth. The young fawn is able to have solid food after two weeks and start rumination after one month (Leslie, 2011).

\section{Case History and Clinical Examination}

A 15 years old female Timorensis deer weighing around $70 \mathrm{~kg}$, managed extensively at Tman Pertanian Universiti (TPU) Universiti Putra Malaysia, was fed with cut and carry grasses and pellet. The history indicates that the previous fawning by this hind was normal with good reproductive performance. Upon observation from a distance, the hind was irritable and restless with fetus's feet dangling at the vulva region "Fig, 1" without abdominal straining. The hind was then isolated in a dark room and specific examination of palpation per vagina was done after proper physical restraining. Hand was inserted through the vagina to examine the presentation, position and posture of the fetus "Fig, 2". The findings indicate that the fetus in posterior longitudinal presentation with dorso- sacral position. Both of the hind limbs were fully extended through the birth canal.

\section{Treatment}

The decision made to do manual traction to assist the hind to expel the fetus. The hind was placed in lateral recumbency position and the birth canal was lubricated with obstetrical gel. The traction was done in line of longitudinal axis with manpower to deliver the fawn. After delivery, the fluid and the mucus were cleared and the fawn was placed in a warm place, wiped until dry especially at the muzzle and neck area to stimulate breathing "Fig, 3". Shortly after that, the fawn was placed near to the mother. It is important not to handle the newborn fawn too long as the hind may not recognized the fawn "Fig, 4". After that, medications given to the mother were Oxytocin (10-20 IU, IM) to help to expel the placenta, antibiotic (Oxytetracycline $20 \mathrm{mg} / \mathrm{kg}$, IM) and analgesic (Flunixin meglumine $2.5 \mathrm{mg} / \mathrm{kg}$, IM) was also given. 


\section{Discussion}

Veterinary assistance for deer's dystocia is important and the time factor is crucial for the survival of the fawn. Therefore deer farmers should be advised to keep a good recording system for tracking the deer and seeking help whenever it needed. Previous study show that pregnancy period in deer is widely variable which make it difficult for the farmer to predict the exact due date of delivery (Chan et al., 2009). In this dystocia case the gestation period was not known exactly by the deer farm keeper's and the only way to observe the deer is during feeding time early in the morning and in the evening, that when the hind was noticed having difficult birth. The incidence of dystocia in farmed deer may increase when the environment condition is not in favor or the management practice is incorrect which lead to increased prevalence of dystocia up to $0.52 \%$ in red deer farms (Audige et al., 2001), 1.1\% in white-tailed deer farms (Haigh et al., 2005) and 5.9\% in elk farms (Woodbury et al., 2006).

However it was the first case of dystocia in this farm and since the hind had successful 10 fawning during her reproductive life, it may indicate that aging as one of the contributing factor. Other changes in the environment and increase human intervention may also contribute toward the incidence. It has been indicated that the incidence of dystocia in live stock significantly linked to the animal age. In ewes dystocia is rare at first birth, but occur often in older ewes that have several pregnancies and/or multiple fetuses. Any interruption in labor process such as human disturbance or sudden change in weather may increase mother's excitability and attribute to maternal stress related factors of dystocia (Pople et al., 2001; Mosdol, 1999). Upon inspection of the current case, there was no indication of uterine contraction; this might be one of the possible causes of the dystocia in which lack of uterine contraction is due to uterine inertia leading to interruption of parturition (Chan et al., 2010).

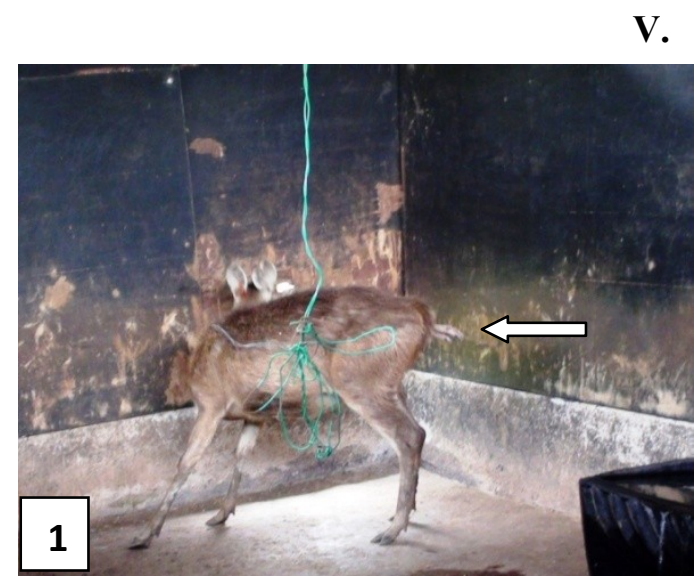

V. Figures

Figure1, limbs of the fawn dangling from the vulva Figure 2, manual traction to assist delivery. (arrow).

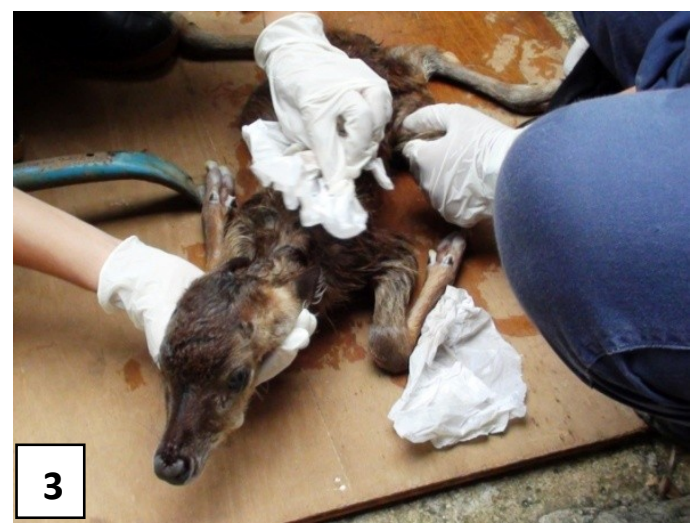

Figure3, the fawn was cleaned after delivery.

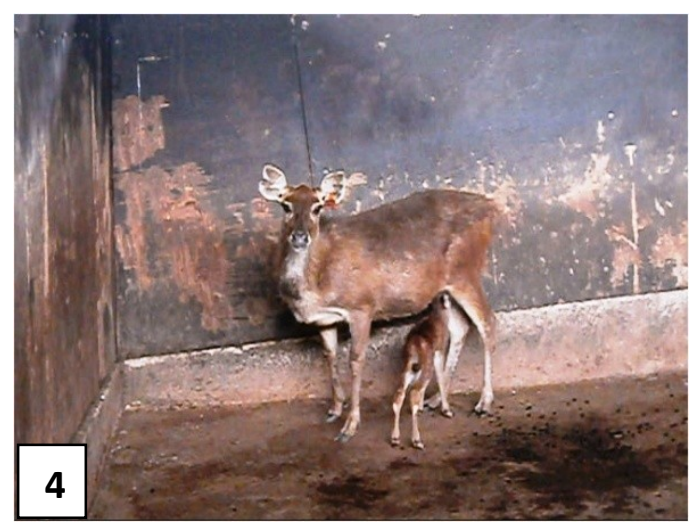

Figure 4, the deer mother and her fawn. 


\section{References}

[1] S.E. Aiello, A. Mays, H.E. Amstutz, D.P. Anderson, S.J. Armour, L.B. Jeffcoh, F.M. Loew and A.M. Wolf, The Merck Veterinary Manual ( $9^{\text {th }}$ Ed. Merck and Co. INC. United States, 2005).

[2] E.L. Bliss, Obstetric and Neonatal Care in Goats. In: Proceedings of the Annual Meeting of the Society of Theriogenology, Orlando, FL, Sept. 16-17, 1988, p283.

[3] J. Engum, and O. Lyngset, Gynecology and Obstetric in the Goats (Iowa State Uni. Vet. 32, 120. 1970).

[4] G. Semiadi, P.D. Muir, T.N. Barry, C.J. Veltman, and J. Hodgson, Grazing patterns of sambar deer (Cervus unicolor) and red deer (Cervus elaphus) in captivity, New Zealand Journal of Agricultural Research, 36, 1993, 253-260.

[5] B.C. Emerson, and M.L. Tate, Genetic analysis of evolutionary relationships among deer subfamily Cervinae, Journal of Heredity, 84 (4), 1993, 266-273.

[6] R.J. Timmins, R. Steinmetz, B.H. Sagar, K.N. Samba, J.W. Duckworth, Md. Anwarul Islam, B. Giman, S. Hedges, A.J. Lynam, J. Fellowes, B.P.L. Chan and T. Evans, Rusa unicolor, 2008, In: Red List of Threatened Species, December 2010.

[7] D.M. Leslie, Rusa unicolor (Artiodactyla: Cervidae), Mammalian Species, 43 (1), 2011 1-30. Doi: 10.1644/871.1.

[8] J.P. Chan, H.Y. Tsai, C.F. Chen, K.C. Tung, and C.C. Chang, The reproductive performance of female Formosan sambar deer (Cervus unicolor swinhoei) in semi-domesticated herds, Theriogenology, 71, 2009, 1156-1161.

[9] L. Audige, P.R. Wilson, and R.S. Morris, Risk factors for dystocia in farmed red deer (Cervus elaphus), Australian Veterinary Journal 9, 2001, 352-357.

[10] J. Haigh, J. Berezowski, and M.R. Woodbury, A cross-sectional study of reproductive indices and fawn mortality in farmed whitetailed deer, Canadian Veterinary Journal, 46, 2005, 413-416.

[11] M.R. Woodbury, J. Berezowski, and J. Haigh, An estimation of reproductive performance of farmed elk (Cervus elaphus) in North America, Canadian Veterinary Journal, 47,2006, 60-64.

[12] N.C. Pople, A.L. Allen, and M.R. Woodbury, A retrospective study of neonatal mortality in farmed elk, Canadian Veterinary Journal, 42, 2001, 925-8.

[13] G. Mosdol, Spontaneous vaginal rupture in pregnant ewes, Veterinary Record, 9, 1999, 38-41.

[14] J.P. Chan, H.Y. Tsai, K.C. Tung, T.H. Hsu, and N.Y. Su, Dystocia in Formosan sambar deer (Cervus unicolor swinhoei) in semidomesticated herds, Veterinary Record, 166, 2010, 786-789. 